\title{
Prevalence and predictors of common mental disorders among Syrian refugees in Istanbul, Turkey: A cross-sectional study
}

Short title: Mental disorders among Syrian refugees in Turkey

Ceren Acarturk, Department of Psychology, Koç University, Istanbul, Turkey

Michael McGrath, London School of Hygiene and Tropical Medicine, Department of Health Services Research and Policy, Public Health and Policy, 15-17 Tavistock Place, London, UK; KIT Royal Tropical Institute, Amsterdam

Bayard Roberts, London School of Hygiene and Tropical Medicine, Department of Health Services Research and Policy, Public Health and Policy, 15-17 Tavistock Place, London, UK Zeynep Ilkkursun, Department of Psychology, Koç University, Istanbul, Turkey

Pim Cuijpers, Department of Clinical, Neuro and Developmental Psychology, Amsterdam Public Health research institute, Vrije Universiteit Amsterdam, The Netherlands

Marit Sijbrandij, Department of Clinical, Neuro and Developmental Psychology, Amsterdam Public Health research institute, Vrije Universiteit Amsterdam, The Netherlands

Egbert Sondorp, KIT Royal Tropical Institute, Amsterdam

Peter Ventevogel, Public Health Section, Division of Programme Management and Support, United High

Commissioner for Refugees

Martin McKee, London School of Hygiene and Tropical Medicine, Department of Health Services Research and Policy, Public Health and Policy, 15-17 Tavistock Place, London, UK

Daniela C. Fuhr, London School of Hygiene and Tropical Medicine, Department of Health Services Research and Policy, Public Health and Policy, 15-17 Tavistock Place, London, UK

on behalf of the STRENGTHS consortium

The STRENGTHS Project is funded under Horizon 2020 - the Framework Programme for Research and Innovation (2014-2020). The content of this article reflects only the authors' views and the European Community is not liable for any use that may be made of the information contained therein.

* Corresponding author: C. Acarturk Department of Psychology, Koç University, Istanbul, Turkey cacarturk@ku.edu.tr 


\section{Abstract \\ Purpose}

The war in Syria has created the greatest refugee crisis in the $21_{\text {st }}$ century. Turkey hosts the highest number of registered Syrian refugees, who are at increased risk of common mental disorders because of their exposure to war, violence and post-displacement stressors. The aim of this paper is to examine the prevalence and predictors of anxiety, depression, and post-traumatic stress disorder (PTSD) symptoms among Syrian refugees living in Turkey.

\section{Methods}

A cross-sectional survey of adult Syrian refugees was conducted between February and May 2018 in Istanbul (Sultanbeyli district). Participants $(\mathrm{N}=1678)$ were randomly selected through the registration system of the district municipality. The Hopkins Symptoms Checklist (HSCL-25) was used to measure anxiety and depression and the Posttraumatic Stress Disorder (PTSD) Checklist (PCL-5) assessed posttraumatic stress. Descriptive and multivariate regression analyses were used.

\section{Results}

The prevalence of symptoms of anxiety, depression and PTSD were 36.1\%, 34.7\% and 19.6\%, respectively. Comorbidity was high. Regression analyses identified several socio-demographic, health and post-displacement variables that predicted common mental disorders including: being female, facing economic difficulties, previous trauma experience, and unmet need for social support, safety, law and justice. A lifetime history of mental health treatment and problems accessing adequate healthcare were associated with depression and anxiety but not with PTSD.

Conclusions Mental disorder symptoms are highly prevalent among Syrian refugees in Turkey. The association with post-displacement factors points to the importance of comprehensive health and social services that can address these social, economic and cultural stressors.

Key words: depression, anxiety, posttraumatic stress disorders, Syrian refugees 


\section{Introduction}

Globally, 13.6 million additional people became forcibly displaced in 2018, now totalling 70.8 million[1]. Among them were more than 25.9 million refugees displaced due to war, conflict or persecution [1]. The war in Syria has created the world's greatest contemporary refugee crisis [1]. Eight years after the start of the war in 2011, 6.7 million Syrians have become refugees or asylum seekers and 6.2 million are internally displaced [2]. The majority of Syrian refugees escaped to neighbouring countries such as Turkey, which now hosts the largest number of Syrian refugees in the world [3]. The majority of Syrian refugees in Turkey are concentrated in the urban centres on the western coast (Istanbul, Izmir and Bursa) and southern border with Syria (Gaziantep, Hatay, Kilis and Şanlıurfa). Istanbul province alone holds 555,951 Syrians or 15\% of Turkey’s total refugee population [4].

During war and flight refugees often face multiple threats to life, loss of family, sexual and physical abuse, and lack of shelter or nutrition [5]. However, refugees also experience many difficulties at post-displacement, including economic problems, language barriers, social isolation and discrimination [6, 7]. As a consequence, they must find ways to cope both with the effects of prior exposure to potentially traumatic events and current stressors, while adapting to a new country and culture [8]. Taken together all these potentially traumatic events and stressful situations before, during and after displacement increase the likelihood for refugees to develop common mental disorders [9-11].

A recent review by the World Health Organization (WHO) estimates the point prevalence of mental disorders (depression, anxiety, post-traumatic stress disorder, bipolar disorder, and schizophrenia) as around $22 \%$ among conflict-affected populations (estimates ranging from 8.1-14.2\% for depression, 9.9-23.5\% for PTSD, and 16.7$28.3 \%$ for anxiety disorders including PTSD) [9]. However, the literature reveals considerable heterogeneity among studies)with variability in results due, potentially, to methodological factors such as differences in assessment tools and sampling, with studies using clinical interviews (instead of self-report instruments), random sampling and larger sample sizes reporting lower rates of mental disorders [12]. Other differences in refugee populations in terms of trauma exposure, migration difficulties, and living conditions in host countries may explain heterogeneity in prevalence rates across studies [13, 14].

There is also consistent and growing evidence that post-displacement living difficulties are independently related to an increase in psychological distress and mental health problems among refugee populations [15-17]. In a study of tortured refugees seeking treatment, post-displacement difficulties were an independent predictor of comorbid posttraumatic stress and depression, associated with lower quality of life [18]. Yet, despite the growing volume of such research worldwide, there is surprisingly little information on the predictors of mental health outcomes among Syrian refugees [19, 20].

The specific objectives of the present study are, first, to report the estimated prevalence of PTSD, depression and anxiety and, second, to investigate factors associated with the occurrence of common mental disorders among Syrian refugees in Turkey. We report on access to mental health services by the study population elsewhere $[21]$. 


\section{Methods}

We conducted a cross-sectional survey of adult Syrian refugees living in Sultanbeyli between February and May 2018. 21,192 Syrians are currently registered in the Sultanbeyli district of Istanbul, representing $6.3 \%$ of the district's total population and making it the largest concentration of Syrians on the Asian side of Istanbul [22]. Many live in overcrowded conditions in rented apartment blocks and experience high levels of poverty [23]. The average number of people living in each household is 6 , and average household income is below the Turkish poverty line $[23,24]$.

Participants were recruited randomly via telephone from a sampling frame extracted from an official registry of Syrian refugees maintained by the Sultanbeyli Municipality. Following an initial telephone call, three further attempts were made to contact potential participants. Participants were excluded from the study if they were nonnative Arabic speakers, below 18 years of age, under the influence of drugs or alcohol, had apparent symptoms of psychosis or had signs of severe intellectual disabilities making it impossible for them to answer the questions. Sample size calculations are presented in Appendix A.

\section{Survey questionnaire}

A survey questionnaire was developed in English and later translated into Arabic. The 247-item questionnaire measured the symptoms of three mental disorders commonly experienced by conflict-affected, refugee populations: depression, anxiety and posttraumatic stress disorder (PTSD). Additional survey items assessed participants' socio-demographic characteristics, history of accessing health services, experiences of potentially traumatic events, post-displacement stressors, and perceived needs (adapted from the HESPER scale [25]).

The Hopkins Symptoms Checklist (HSCL-25) is a 25-item screening instrument for depression and anxiety that is widely used in conflict affected populations including Syrian refugees [17, 26]. It measures the severity of mental health symptoms experienced in the last week on a 4-point scale ranging from 1 ("Not at all") to 4 ("Extremely"). A mean score is calculated for the first 10 items (anxiety symptoms) and the final 15 items (depressive symptoms). Cut-off scores of $\geq 2.0$ for symptomatic anxiety and of $\geq 2.1$ for symptomatic depression were used, based on a validation study of the instrument in another conflict-affected, Arabic-speaking population [27].

The PTSD Checklist (PCL-5) asks participants about the extent to which they have been bothered by 20 symptoms of PTSD in the past month on a five-point scale ranging from 0 ("Not at all") to 4 ("Extremely"). The checklist contains four symptom clusters that align with a DSM-5 clinical diagnosis of PTSD. An individual's responses are summed to produce a score between 0 and 80 . A cut-off score of $\geq 33$ was used as an indicator of symptomatic PTSD as established in other conflict-affected populations [28]. 
The construct validity of both instruments was examined using confirmatory factor analysis and model fit assessed using established thresholds [29]. For the HSCL-25, a two-factor structure with correlated depression and anxiety factors was found to have adequate to good fit in our sample (root mean square error of approximation (RMSEA): 0.055 [95\%CI 0.052-0.058]; comparative fit index (CFI): 0.904; standardised root mean square residual (SRMR): 0.039). For the PCL-5, a four-factor model based on correlated DSM-5 PTSD symptom clusters (intrusion, avoidance, negative cognition and hyperarousal) similarly showed adequate to good fit (RMSEA: 0.043 [0.040-0.047]; CFI: 0.936; SRMR 0.033). Reliability was assessed using Raykov’s rho ( $\rho>$ 0.80 'good', $\rho>0.70$ 'acceptable') [30] and Cronbach's alpha ( $\alpha>0.80$ 'good', $\alpha>0.80$ 'acceptable') Both the depression $(\rho=0.88 ; \alpha=0.87)$ and anxiety $(\rho=0.87 ; \alpha=0.86)$ factors showed good reliability in our sample. Reliability coefficients for PCL-5 factors were acceptable (intrusion: $\rho=0.78, \alpha=0.77$; avoidance: $\rho=0.72, \alpha$ $=0.72$; negative cognition: $\rho=0.72, \alpha=0.71)$, apart from hyperarousal $(\rho=0.69, \alpha=0.68)$.

Trained and experienced interviewers conducted the assessment. Interviewers were fluent in Arabic and received training on the aims of the study, enumeration techniques, quality standards, ethical considerations, and sensitivity to the needs of respondents prior of conducting the survey. The questionnaire was delivered face-toface in a private space at a Syrian community centre in Sultanbeyli and participants were matched to interviewers by gender. Data were collected using tablet computers. Participants were provided with an information sheet, and verbal and written consent were obtained immediately prior to interview. A gift card valued at 20 Turkish Lira ( $€ 5)$ was provided to compensate participants for their time. The study was approved by the ethics committees at Istanbul Şehir University and the London School of Hygiene \& Tropical Medicine. The study followed ethical principles of medical research as outlined by the Declaration of Helsinki. The study protocol can be obtained from the corresponding author.

\section{Analysis:}

Based on agreed cut-off scores, three binary mental health outcomes were created (symptoms of depression, anxiety and PTSD). Symptom scores were not calculated for participants who failed to respond to at least twothirds of items relating to a measure (PTSD) or sub-measure (depression and anxiety), as per instrument guidelines. Between group differences in mental health outcomes were explored using descriptive statistics (chisquared tests, t-tests, Pearson correlation coefficients).

Based on previous empirical research [7- 11] and clinical judgement, potential explanatory variables were chosen for logistic regression analysis: sociodemographic variables (age, sex, education, household economic situation), period of displacement, experiences of potentially traumatic events, post-displacement life stressors, and health variables (lifetime history of mental health treatment, living with a chronic disease or disability). These variables were tested for multicollinearity (variance inflation factor: range 1.04-1.68) and visually inspected for influential outliers using scatterplots [32]. Multivariable linear regression using continuous outcome scores was used to test the sensitivity of these associations to the agreed cut-off scores (Appendix B) All analysis was conducted in Stata IC 14.0 [31]. 


\section{Results}

\section{Sample characteristics}

1,678 people participated in our survey, representing a response rate of 59\%. Sample characteristics are presented in Table 1. The median age of participants was 34 years (range 18-88). The age-sex profile of our sample broadly matched that of all Syrians under temporary protection in Turkey[4], although females and younger adults appeared to be over-represented in our sample (52\% females compared with $44 \%$ nationally).

Ninety-three percent of women described themselves as housewives and $44 \%$ of males reported to have regular, paid work. Only $4.5 \%$ of participants reported their household economic situation as 'good' or 'very good'. Median years of education was 6 years (range 0,23). The mean period of displacement from Syria was 3.4 years $(\mathrm{SD}=1.43)$ and mean length of time living in Sultanbeyli was 2.9 years $(\mathrm{SD}=1.24)$.

Table 1: Sample characteristics $(n=1,678)$

\section{Exposure to potentially traumatic events and post-displacement stressors}

From our sample, 455 males (56\%) and 313 females (36\%) reported experiencing or witnessing others experience a potentially traumatic event. The most frequently reported problems since arriving in Sultanbeyli were "feeling very distressed" (41\%), "not getting enough emotional support" (31\%) and being "unable to access adequate healthcare" (29\%) (Table 1). Reponses to these survey items differed significantly between men and women for two items: "not having enough information about the aid that is available or what is happening in Syria" (males $34 \%$, females $24 \%, \chi^{2}=21.8, \mathrm{p}<0.001$ ) and "an inadequate system for law and justice or not knowing enough about legal rights" (males $23 \%$, females $13 \%, \chi^{2}=25.9 \mathrm{p}<0.001$ ). 


\section{Mental health outcomes}

The prevalence of symptoms of PTSD, depression, and anxiety was $19.6 \%, 36.1 \%$ and $34.7 \%$ respectively (Table 2). Almost half of our participants (46.9\%) were experiencing symptoms of at least one mental disorder, $30.6 \%$ symptoms of more than one mental disorder, and $14.2 \%$ symptoms of all three disorders. Comorbid symptoms of depression and anxiety were experienced by $25.6 \%$ of participants, comorbid symptoms of depression and PTSD by $16.3 \%$, and comorbid symptoms of anxiety and PTSD by $15.7 \%$. There were moderate to strong, linear associations between depression and anxiety scores ( $r=.74,95 \%$ CI [.72-.76], $\mathrm{p} \leq 0.001)$, depression and PTSD scores ( $\mathrm{r}=.74,95 \% \mathrm{CI}[.71-.76], \mathrm{p} \leq 0.001)$ and PTSD and anxiety scores $(\mathrm{r}=.70,95 \% \mathrm{CI}$ [.67-.72], $\mathrm{p} \leq 0.001)$ [32].

Significant differences by gender in mean symptom scores were observed for depression (males 1.8 [SD $=0.64]$; females $2.1[\mathrm{SD}=0.69] ; \mathrm{t}=-5.1 \mathrm{p}<0.001$ ), anxiety (males 1.7 [SD $=0.64$ ]; females 1.9 [SD $=0.71] ; \mathrm{t}=-7.4$ $\mathrm{p}<0.001$ ), but not PTSD (males $20.2[\mathrm{SD}=13.31$ ); females $21.2[\mathrm{SD}=13.71] ; \mathrm{t}=-1.5 \mathrm{p}=0.134$ ).

Table 2: Common mental health outcomes by sex, counts and percent $(n=1,678)$

\section{Factors associated with mental disorders}

After adjusting for sociodemographic characteristics, displacement time, post-displacement stressors, healthrelated variables and potential traumatic exposure, there was a strong association between gender and mental disorders, with women around twice as likely to experience PTSD (OR 1.84 [95\% CI 1.33-2.54]), depression (OR 1.86 [95\% CI 1.44-2.42]), and anxiety (OR 2.44 [95\% CI 1.87-3.19]), holding all other variables constant (Table 3). Good household economic situation was associated with significantly better mental health outcomes compared to those living in households in poor economic circumstances (PTSD: OR 0.19 [95\% CI 0.05-0.64]; depression: OR 0.16 [95\% CI 0.07-0.38]; anxiety: OR 0.26 [95\% CI 0.12-0.59]).

All three mental health outcomes were positively associated with "feeling as if you or your family are not safe and protected", "experiencing problems in your community with law and justice" and "not receiving enough emotional support from others" and having "ever experienced a potentially traumatic event". Having a long-term illness or disability was associated with PTSD (OR 2.05 [95\% CI 1.55-2.70]), depression (OR 1.86 [95\% CI 1.48-2.34]), and anxiety (OR 2.18 [95\% CI 1.73-2.76]). A lifetime history of mental health treatment (defined as ever having received a session of psychological counselling or therapy, or having been admitted for overnight stay in a healthcare facility for your emotions, nerves or mental health) was associated with both depression (OR 2.00 [95\% CI 1.35-2.97]) and anxiety (OR 1.95 [95\% CI 1.32-2.89]), but not PTSD. Reporting problems accessing adequate healthcare since arriving in Sultanbeyli was similarly associated with depression (OR 1.40 [95\% CI 1.06-1.85]) and anxiety (OR 1.40 [95\% CI 1.06-1.85]), but not PTSD.

Table 3: Bivariate and multiple logistic regression analysis of variables associated with common mental health outcomes 


\section{Discussion}

The aim of this paper was to examine the prevalence and predictors of anxiety, depression, and post-traumatic stress disorder (PTSD) symptoms among Syrian refugees living in Turkey. This is one of the first studies which reports data on the prevalence and predictors of common mental disorders among resettled adult Syrian refugees in Turkey using a large random sample. The prevalence rates for anxiety, depression and PTSD symptoms was $36.1 \%, 34.7 \%$ and $19.6 \%$, respectively. Almost half of participants in our study had symptoms of at least one mental disorder $(46.9 \%)$ and one third of participants had symptoms of more than one mental disorder (30.6\%). Our prevalence for PTSD, anxiety and depression are in line with previously estimated prevalence rates of anxiety (13.5\% - 31.8\%) [5, 17], depression (14.5\% - 44\%) [5, 17, 33, 34], and PTSD (11.4\%-83.4\%) [5, 17, 33, 35, 36] found among Syrian refugees in Turkey and European host countries such as Germany, Sweden, and Greece [5, 17]. However, a recent meta-analysis on mental disorders among conflict-affected populations reported lower pooled prevalence rates for anxiety, PTSD, and depression $(21.7 \% \%, 15.3 \%$, and $10.8 \%$ respectively) [9]. There is evidence that self-reporting instruments tend to overestimate the prevalence of mental disorders [11] by a factor of 1.5 to 2 [9].

Consistent with other research, being female was associated with the occurrence of depression, anxiety and PTSD [33-35, 37-39]. Studies among Syrian refugees living in tent cities in Turkey confirm that finding and found female refugees to be at higher risk for PTSD [33, 35] and depression [33]. This might be due to biological factors $[33,35]$ but also other environmental circumstances such as the experience of gender-based violence that women might have been exposed to during war and displacement [40, 41]. Moreover, postdisplacement living difficulties, such as restrictions by the family, early marriages or abuse are postulated to contribute to the higher prevalence of psychological distress among refugee women [41-43].

The finding that poor economic conditions were associated with mental disorders among our study population is in line with a large body of research on refugees [37,44]. For example, a study with Sudanese refugees in Canada, reported that those experiencing economic hardship were 2.6-3.9 times more likely to suffer from loss of sleep, psychological distress, depression and bad memories [45]. In another study with 2,399 humanitarian migrants in Australia, Chen and colleagues (2017) found that economic stressors are significantly associated with PTSD and severe mental illness [7].

The association between common mental disorders and age was not statistically significant in our study. The literature reports contradictory findings showing that age can either have a positive or negative association with mental ill health among refugees $[17,18,36,46]$. We found that experiencing or witnessing a potentially traumatic event was significantly associated with a higher likelihood of showing symptoms of depression, anxiety or PTSD. A previous study with Syrian refugees in Sweden showed exposure to potentially traumatic events to be related to mental ill health including symptoms of depression, anxiety and PTSD [17]. There is a growing literature indicating that among refugees, not only distal trauma, but also proximal post displacement factors such as unmet needs are related to the occurrence of mental disorders [15, 47]. Jordans and colleagues (2012) assessed the relationship between past traumatic events, current perceived needs and distress among Iraqi 
and Bhutanese refugees in Jordan and Nepal respectively [16]. In support of the view that refugees should receive integrated interventions targeting daily stressors and war-trauma related stressors [15], they found that current unmet perceived needs mediate the association between past trauma and current psychological distress. Consistent with this, the present study found that Syrian refugees who have current problems with law and justice in their own community (due to either inadequate legal and judicial systems or due to lack of information on their legal rights, and who do not feel safe and protected) have a higher likelihood of having mental health problems.

Our finding that lifetime mental health treatment was associated with a higher likelihood of having symptoms of depression or anxiety is confirmed by previous research. Earlier studies with Syrian refugees living in camps in Turkey indicated that having previous mental health problems is a risk factor for depression [33] and PTSD [33, 35]. Having previous mental health problems may decrease the ability to cope with previous trauma and/or postdisplacement stressors.

Having a long-term illness or disability appeared to be significantly associated with symptoms of depression, anxiety and PTSD in our study. Similarly, in a study of Syrian refugees living in Jordan, depression was found to be significantly associated with chronic diseases [48]. There is a well-established literature that physical and mental health problems tend to cluster [49] and this has also been reported among refugees [50]. Chronic longterm illness or disability might make refugees more vulnerable to post-displacement stressors increasing the susceptibility to mental disorders.

The present study has a few limitations. Firstly, the instruments we used to measure depression, anxiety and PTSD have not been validated among Syrians in Turkey though they had been used with Syrian refugees elsewhere in previous studies and showed good reliability and validity in the present study [17, 51]. Secondly, instead of clinician-administered diagnostic interviews, we assessed symptoms of mental health disorders through self-report measures which are known to inflate prevalence estimates compared to diagnostic interviews [9]. Thirdly, the sample included registered refugees only, and it is possible that unregistered Syrian refugees may have different and more severe mental health needs. Fourthly, not all potential predictors of poor mental health such as potential pre-migration risk factors, number and type of traumatic events, experiences during 'flight' and other potential post-displacement stressors were explored as they were not measured in the survey questionnaire. Finally, due to the cross-sectional nature of this study, we were not able to examine causality between predictors and mental health outcomes.

\section{Conclusion}

Our study has shown that symptoms of depression, anxiety and PTSD are common among Syrian refugees living in Turkey and tend to cluster. A significant association between post-displacement living conditions and mental ill health among refugees has been detected. Service providers and policy makers should push for integrated services, taking into account the effect of economic, social and cultural hardship on mental health among refugees in their host country. To improve mental health outcomes among refugees, it is important that policies and health services also target contextual and societal conditions that give rise to post-displacement stressors. 


\section{Authors' Contributions}

CA wrote the first draft of the report and was responsible for overseeing data collection in Turkey. DF and BR designed the survey and were involved in data management. MMG statistically analysed the data. ZI, PC, MS, EG, PV, and MMK contributed to the interpretation of data and critically revised the paper. All authors approved the final version.

Financial Support: This study was funded through the STRENGTHS (Syrian REfuGees MeNTal HealTH Care Systems) project. The STRENGTHS project is funded under Horizon 2020 - the Framework Programme for Research and Innovation (2014-2020). The content of this article reflects only the authors' views and the European Community is not liable for any use that may be made of the information contained therein.

Availability of data: Further information on the data supporting the findings of this study can be obtained from Daniela Fuhr or Bayard Roberts (e-mail address:Daniela.fuhr@1shtm.ac.uk or bayard.roberts@1shtm.ac.uk).

Conflict of Interests: The authors declare that there are no conflicts of interests.

\section{Acknowledgement}

Electronic data solutions were provided by LSHTM Open Data Kit (odk.lshtm.ac.uk).

\section{References}

1. UNHCR (2018) Global Trends Forced Displacement in 2018

2. UNHCR (2019) Operational Portal: Refugee Situation. https://data2.unhcr.org/en/situations/syria

3. UNHCR (2019) Figures at a Glance. https://www.unhcr.org/figures-at-a-glance.html

4. Republic of Turkey DGoMM Temporary Protection Istatistics. https://www.goc.gov.tr/gecicikoruma5638

5. Georgiadou E, Zbidat A, Schmitt GM, Erim Y (2018) Prevalence of mental distress among Syrian refugees with residence permission in Germany: A registry-based study. Front Psychiatry. https://doi.org/10.3389/fpsyt.2018.00393

6. Ben Farhat J, Blanchet K, Juul Bjertrup P, et al (2018) Syrian refugees in Greece: Experience with violence, mental health status, and access to information during the journey and while in Greece. BMC Med. https://doi.org/10.1186/s12916-018-1028-4

7. Chen W, Hall BJ, Ling L, Renzaho AM (2017) Pre-migration and post-migration factors associated with mental health in humanitarian migrants in Australia and the moderation effect of post-migration stressors: findings from the first wave data of the BNLA cohort study. The Lancet Psychiatry. https://doi.org/10.1016/S2215-0366(17)30032-9 
8. Kartal D, Kiropoulos L (2016) Effects of acculturative stress on PTSD, depressive, and anxiety symptoms among refugees resettled in Australia and Austria. Eur J Psychotraumatol. https://doi.org/10.3402/ejpt.v7.28711

9. Charlson F, van Ommeren M, Flaxman A, et al (2019) New WHO prevalence estimates of mental disorders in conflict settings: a systematic review and meta-analysis. Lancet. https://doi.org/10.1016/s0140-6736(19)30934-1

10. Fazel M, Wheeler J, Danesh J (2005) Prevalence of serious mental disorder in 7000 refugees resettled in western countries: A systematic review. Lancet. https://doi.org/10.1016/S0140-6736(05)61027-6

11. Steel Z, Chey T, Silove D, et al (2009) Association of torture and other potentially traumatic events with mental health outcomes among populations exposed to mass conflict and displacement: A systematic review and meta-analysis. JAMA - J. Am. Med. Assoc.

12. Turrini G, Purgato M, Ballette F, et al (2017) Common mental disorders in asylum seekers and refugees: Umbrella review of prevalence and intervention studies. Int J Ment Health Syst. https://doi.org/10.1186/s13033-017-0156-0

13. Morina N, Akhtar A, Barth J, Schnyder U (2018) Psychiatric disorders in refugees and internally displaced persons after forced displacement: A systematic review. Front. Psychiatry

14. Schick M, Morina N, Mistridis P, et al (2018) Changes in post-migration living difficulties predict treatment outcome in traumatized refugees. Front Psychiatry. https://doi.org/10.3389/fpsyt.2018.00476

15. Miller KE, Rasmussen A (2017) The mental health of civilians displaced by armed conflict: An ecological model of refugee distress. Epidemiol Psychiatr Sci.

https://doi.org/10.1017/S2045796016000172

16. Jordans MJD, Semrau M, Thornicroft G, Van Ommeren M (2012) Role of current perceived needs in explaining the association between past trauma exposure and distress in humanitarian settings in Jordan and Nepal. Br J Psychiatry. https://doi.org/10.1192/bjp.bp.111.102137

17. Tinghög P, Malm A, Arwidson C, et al (2017) Prevalence of mental ill health, traumas and postmigration stress among refugees from Syria resettled in Sweden after 2011: A population-based survey. BMJ Open

18. Nickerson A, Schick M, Schnyder U, et al (2017) Comorbidity of Posttraumatic Stress Disorder and Depression in Tortured, Treatment-Seeking Refugees. J Trauma Stress. https://doi.org/10.1002/jts.22205

19. Satinsky E, Fuhr DC, Woodward A, et al (2019) Mental health care utilisation and access among refugees and asylum seekers in Europe: A systematic review. Health Policy (New York). https://doi.org/10.1016/j.healthpol.2019.02.007

20. Hendrickx M, Woodward A, Fuhr D, Sondorp E RB (2019) The burden of mental disorders and access to mental health and psychosocial support services in Syria and among Syrian refugees in neighbouring countries: A systematic review. Eur J Public Health.

21. Fuhr DC, Acarturk C, McGrath M et al (2020) Treatment gap and mental health service use among Syrian refugees in Turkey: A cross-sectional survey. Epidemiol Psychiatr Sci. https://doi.org/10.1017/S2045796019000660

22. Elicin Y (2018) Refugee Crisis and Local Responses: An Assessment of Local Capacities to Deal with Migration Influxes in Istanbul. Croat Comp PUBLIC Adm. https://doi.org/10.31297/hkju.18.1.3 
23. Erdoğan M (2017) 6. Yılında Türkiye'deki Suriyeliler: Sultanbeyli Örneği.

http://panel.stgm.org.tr/vera/app/var/files/6/-/6-yilinda-turkiyedeki-suriyeliler-sultanbeyli-ornegi.pdf

24. Asgari Ücret Tespit Komisyonu Kararı (2016) TC Resmi Gazate.

https://www.resmigazete.gov.tr/eskiler/2016/12/20161230-22.pdf

25. World Health Organization \& King's College London (2011) The Humanitarian Emergency Settings Perceived Needs Scale (HESPER): Manual with Scale. Geneva: World Health Organization

26. Kleijn WC, Hovens JE, Rodenburg JJ (2001) Posttraumatic stress symptoms in refugees: Assessments with the Harvard Trauma Questionnaire and the Hopkins symptom checklist-25 in different languages. Psychol Rep. https://doi.org/10.2466/pr0.2001.88.2.527

27. Mahfoud Z, Kobeissi L, Peters TJ, et al (2013) The Arabic Validation of the Hopkins Symptoms Checklist-25 against MINI in a Disadvantaged Suburb of Beirut, Lebanon. Int J Educ Psychol Assess

28. Bovin MJ, Marx BP, Weathers FW, et al (2016) Psychometric properties of the PTSD checklist for diagnostic and statistical manual of mental disorders-fifth edition (PCL-5) in veterans. Psychol Assess. https://doi.org/10.1037/pas0000254

29. Hu L \& Bentler PM (1999) Cutoff criteria for fit indexes in covariance structure analysis: Conventional criteria versus new alternatives. Structural Equation Modeling: A Multidisciplinary Journal. https://doi.org/10.1080/10705519909540118

30. Raykov T (1997) Estimation of composite reliability for congeneric measures. Applied Psychological Measurement. https://doi.org/10.1177/01466216970212006

31. StataCorp (2015) Stata Statistical Software: Release 14. College Station

32. Schober P, Schwarte LA (2018) Correlation coefficients: Appropriate use and interpretation. Anesth Analg. https://doi.org/10.1213/ANE.0000000000002864

33. Acarturk C, Cetinkaya M, Senay I, et al (2018) Prevalence and predictors of posttraumatic stress and depression symptoms among syrian refugees in a refugee camp. J Nerv Ment Dis. https://doi.org/10.1097/NMD.0000000000000693

34. Poole DN, Hedt-Gauthier B, Liao S, et al (2018) Major depressive disorder prevalence and risk factors among Syrian asylum seekers in Greece. BMC Public Health. https://doi.org/10.1186/s12889-018-5822X

35. Alpak G, Unal A, Bulbul F, et al (2015) Post-traumatic stress disorder among Syrian refugees in Turkey: A cross-sectional study. Int J Psychiatry Clin Pract. https://doi.org/10.3109/13651501.2014.961930

36. Chung MC, AlQarni N, AlMazrouei M, et al (2018) Posttraumatic Stress Disorder and Psychiatric Comorbidity among Syrian Refugees of Different Ages: the Role of Trauma Centrality. Psychiatr Q. https://doi.org/10.1007/s11126-018-9586-3

37. Porter M, Haslam N (2005) Predisplacement and postdisplacement factors associated with mental health of refugees and internally displaced persons: A meta-analysis. J. Am. Med. Assoc.

38. Schubert CC, Punamäki RL (2011) Mental health among torture survivors: Cultural background, refugee status and gender. Nord J Psychiatry. https://doi.org/10.3109/08039488.2010.514943

39. Song SJ, Subica A, Kaplan C, et al (2018) Predicting the mental health and functioning of torture survivors. J Nerv Ment Dis. https://doi.org/10.1097/NMD.0000000000000678

40. Schweitzer RD, Vromans L, Brough M, et al (2018) Recently resettled refugee women-at-risk in 
Australia evidence high levels of psychiatric symptoms: Individual, trauma and post-migration factors predict outcomes. BMC Med. https://doi.org/10.1186/s12916-018-1143-2

41. Hassan G, Ventevogel P, Jefee-Bahloul H, et al (2016) Mental health and psychosocial wellbeing of Syrians affected by armed conflict. Epidemiol Psychiatr Sci. https://doi.org/10.1017/S2045796016000044

42. Boswall K, Akash R Al (2015) Personal perspectives of protracted displacement: an ethnographic insight into the isolation and coping mechanisms of Syrian women and girls living as urban refugees in northern Jordan. Intervention. https://doi.org/10.1097/WTF.0000000000000097

43. Wringe A, Yankah E, Parks T, et al (2019) Altered social trajectories and risks of violence among young Syrian women seeking refuge in Turkey: A qualitative study. BMC Womens Health. https://doi.org/10.1186/s12905-019-0710-9

44. Chu T, Keller AS, Rasmussen A (2013) Effects of post-migration factors on PTSD outcomes among immigrant survivors of political violence. J Immigr Minor Heal. https://doi.org/10.1007/s10903-0129696-1

45. Simich L, Hamilton H, Baya BK (2006) Mental Distress, Economic Hardship and Expectations of Life in Canada among Sudanese Newcomers. Transcult Psychiatry. https://doi.org/10.1177/1363461506066985

46. Steel Z, Silove D, Brooks R, et al (2006) Impact of immigration detention and temporary protection on the mental health of refugees. Br J Psychiatry. https://doi.org/10.1192/bjp.bp.104.007864

47. Riley A, Varner A, Ventevogel P, et al (2017) Daily stressors, trauma exposure, and mental health among stateless Rohingya refugees in Bangladesh. Transcult Psychiatry. https://doi.org/10.1177/1363461517705571

48. Gammouh OS, Al-Smadi AM, Tawalbeh LI, Khoury LS (2015) Chronic diseases, lack of medications, and depression among syrian refugees in Jordan, 2013-2014. Prev. Chronic Dis.

49. Prince M, Patel V, Saxena S, et al (2007) No health without mental health. Lancet

50. Mulugeta W, Xue H, Glick M, et al (2019) Burden of Mental Illness and Non-communicable Diseases and Risk Factors for Mental Illness Among Refugees in Buffalo, NY, 2004-2014. J Racial Ethn Heal Disparities. https://doi.org/10.1007/s40615-018-0498-6

51. Javanbakht A, Rosenberg D, Haddad L, Arfken CL (2018) Mental Health in Syrian Refugee Children Resettling in the United States: War Trauma, Migration, and the Role of Parental Stress. J. Am. Acad. Child Adolesc. Psychiatry 